\section{3}

Recebido em: 20.11.2018 Aprovado em: 15.12.2018. O artigo é resultado da pesquisa Modos de vida urbanos: reflexões sobre o consumo e direitos, em curso desde 2017, no Departamento de Ciências Domésticas da Universidade Federal Rural de Pernambuco, a partir do Observatório da Família, em parceria com o Programa de Pós Graduação em Consumo, Cotidiano Desenvolvimento Social.

** Doutora pelo Programa de PósGraduação em Ciências Sociais da Universidade do Estado do Rio de Janeiro. professora do Programa de Mestrado em Consumo, Cotidiano Desenvolvimento Social da UFRPE. Email: aragaouchoa@hotmail.com Doutoranda em Direito Público pela Faculdade de Direito da Universidade de Coimbra Email: mlygia4@hotmail.com

Mestra em Extensão Rural e Desenvolvimento Local

POSMEX/UFRPE. Professora de Desenvolvimento Humano Coordenadora do curso de Graduação em Ciências do Consumo da UFRPE. Email:

michelle8maciel@gmail.com

Doutora em Jornalismo, pela Universidade Autônoma de Barcelona. Professora Associada da Universidade Federal de Alagoas. Email: 1sduquearrazola@gmail.com

\title{
Encarceramento feminino, tráfico de drogas e maternidade:
} cotidianos subalternos dentro e fora da prisão*

Female incarceration, drug trafficking and maternity: daily subordinates inside and outside the prison

Raquel Aragão Uchôa Fernandes***, Maria Lygia Almeida e Silva Koike ${ }^{* * *}$, Michelle Cristina Rufino Maciel $^{* * * *}$, Laura Susana Duque-Arrazola ${ }^{* * * * *}$

Resumo: A proposta deste estudo é revelar cotidianos subalternos de mulheres que vivenciaram ou vivenciam o encarceramento. O objetivo deste estudo é identificar e analisar as vivências de mulheres e famílias subalternas na cidade do Recife com trajetória de encarceramento, a partir da percepção de profissionais que atuam cotidianamente com estas mulheres. Nesta etapa da pesquisa buscamos compreender as relações percebidas entre as subjetividades destas mulheres e o consumo, através da identificação e relato das táticas criadas/utilizadas por estas mulheres para o acesso a bens de consumo individuais e coletivos. A metodologia utilizada foi a de grupo focal e pesquisa ação. Neste artigo serão apresentados dados parciais com o recorte para a relação maternidade e cárcere, com ênfase para os efeitos do encarceramento em massa no cotidiano destas mulheres. Os resultados apontam que há uma reprodução geracional de trajetórias subalternas na história de vida destas mulheres, agravada pela vivência do/no cárcere, com incidência sobre as suas subjetividades, estabelecimento de relações com as pessoas, bens e serviços.

Palavras-chave: Consumo; encarceramento; gênero, tráfico de drogas
Abstract: The purpose of this study is to reveal daily subordinates of women who experienced or experience incarceration. The objective of this study is to identify and analyze the experiences of women and subaltern families in the city of Recife, with trajectory of incarceration, based on the perception of professionals who work daily with these women. At this stage of the research we seek to understand the perceived relationships between the subjectivities of these women and consumption, through the identification and reporting of the tactics created / used by these women to access individual and collective consumer goods. The methodology used was that of focus group and research action. In this article we will present partial data with the cut for the relationship between motherhood and jail, with emphasis on the effects of mass incarceration in the daily life of these women. The results indicate that there is a generational reproduction of subaltern trajectories in the life history of these women, aggravated by the experience of / in prison, affecting their subjectivities, establishing relationships with people, goods and services.

Keywords: consumption, incarceration, gender, drug trafficking 


\section{INTRODUÇÃO}

O presente artigo é resultado do projeto de pesquisa intitulado Modos de vida urbano: reflexões sobre o consumo $e$ direitos à cidade no sistema prisional feminino, vinculado aos estudos e pesquisas do Observatório da Família e do Programa de Pós-Graduação em Consumo, Cotidiano e Desenvolvimento Social PGCDS, do Departamento de Ciências Domésticas da Universidade Federal Rural de Pernambuco. Esse estudo tem viabilizado aproximações e articulações com instituições e pesquisadores/as de diversas campos do conhecimento (Direito, Ciências Sociais, Serviço Social, Economia Doméstica, Psicologia, entre outros) que trabalham diretamente com a problemática do encarceramento de mulheres no Estado de Pernambuco.

$\mathrm{Na}$ presente pesquisa partimos do pressuposto de que o encarceramento é um dos resultados de trajetórias de subalternidade. Inferimos que o cotidiano marcado pela precariedade vincula estes sujeitos ao que Jessé Souza (2016) chama provocativamente de Ralé: "[...] uma classe inteira de indivíduos, não só sem capital cultural nem econômico em qualquer medida significativa, mas desprovida [...] das precondições sociais, morais e culturais que permitem essa apropriação" (SOUZA, 2016).

Nesta pesquisa trabalhamos com o conceito de subalternidade a partir das contribuições de Gayatri Spivak e Edward Thompson. Para a autora, os subalternos correspondem aos alijados da fala, "as camadas mais baixas da sociedade constituídas pelos modos específicos de exclusão dos mercados, da representação política e legal, e da possibilidade de se tornarem membros plenos no estrato social dominante" (SPIVAK, 2010, p.14). Para Thompson (2011), a subalternidade está associada ao conceito de experiência, da trajetória enquanto classe em uma determinada formação social.

Segundo dados do International Centre for Prison Studies, há aproximadamente 700.000 mulheres encarceradas no mundo, e o Brasil surge como a quinta maior população carcerária feminina do mundo. Tal prerrogativa é confirmada pelos dados apresentados no Levantamento Nacional de Informações Penitenciárias sobre as Mulheres - Infopen, de 2018. É fato que ocorreu um boom do encarceramento feminino no Brasil. Em 2000 havia aproximadamente 10.112 mulheres presas; já em 2014, esta população havia quadruplicado.

Consideramos nesta pesquisa que o consumo acaba por ter um papel determinante não apenas sobre o cotidiano dos indivíduos, mas também nas formas como estes/as estruturam ou reforçam elementos identitários e estabelecem relações. A abordagem sobre as subjetividades e as representações pôde auxiliar-nos neste processo de buscar compreender as percepções destes sujeitos sobre seu cotidiano, sua trajetória e o consumo enquanto expressão de determinado modo de vida e formas de identificação na sociedade.

Neste sentido, para a análise de como os sujeitos se movimentam em meio a esta ordem social, recoremos a Certeau 
(1994) ao analisar o cotidiano a partir de "práticas comuns", o que ele denomina de as "artes de fazer" dos/as praticantes, as operações astuciosas e clandestinas frente às "estratégias" formuladas pelos detentores de poder.

Para Certeau, os indivíduos "comuns", "alijados de voz", como referidos por Spivak, em seu cotidiano apresentam formas de agência, de produção de significados, não apenas de mera e passiva apropriação uniforme, feita de puro conformismo às imposições do mercado e dos poderes sociais. Neste trabalho, consideramos que a vivência do tempo do cárcere e os desafios do pós cárcere para as mulheres pobres, acabam revelando um repertório bastante significativo de táticas de enfrentamento as diferentes expressões do alijamento de poder manifestas em seus cotidianos

No Estado de Pernambuco, a população carcerária feminina atualmente está em torno de 1.500 mulheres, e o motivo do encarceramento para a maioria dos casos está vinculado ao tráfico de drogas (MECANISMO, 2016). Geralmente são mulheres jovens, negras ou pardas, de periferia, com baixo grau de instrução formal, responsáveis diretas pelo provimento das unidades familiares através de renda obtida em ocupações parciais, precárias e/ou ilegais, mães de, no mínimo, um/a filho/a e com algum parente seja irmão, filho, marido ou companheiro - preso..

Em síntese, os dados relacionados ao perfil das mulheres com vivência do cárcere é de trajetórias de reprodução intergeracional da pobreza, de direitos fundamentais negligenciados. Em função desta vulnerabilidade, tornam-se elementos fáceis de serem exploradas pelos grandes traficantes, principalmente na preparação, no armazenamento e na distribuição das drogas para os consumidores finais. Usualmente não são as gerentes das facções, ou estão longe de enriquecerem com esta atividade, ainda que na literatura tenhamos encontrado registros sobre uma mudança no perfil de participação das mulheres no universo do tráfico de drogas, a citar o estudo de Luciana Ribeiro de Oliveira, Crime é "coisa de mulher": identidades de gênero e identificações com a prática de crimes em posição de liderança entre mulheres jovens na cidade de Recife/PE. Não resta qualquer dúvida que as mulheres encarceradas por envolvimento com o tráfico de drogas cometeram um ato criminoso, um ilícito penal, porém é essencial lançar um olhar menos dogmático e mais empático sobre esta realidade social e econômica a qual estas mulheres foram submetidas.

É bastante comum o relato de mulheres mais velhas que foram presas por associação ao tráfico porque seus filhos ou netos armazenavam drogas em suas casas; mulheres mais novas que traficaram porque não encontraram oportunidade de emprego formal e precisavam arcar com as despesas de saúde, alimentação e educação dos filhos, por terem sido abandonadas pelos seus companheiros ou, muito comumente, por seus maridos estarem presos. E não podemos esquecer ainda a realidade opressora das mulheres (das mais variadas idades) que são obrigadas a entrar em unidades prisionais com drogas como forma de pagamento das dívidas que seus companheiros/filhos/netos contraíram dentro da prisão. 


\section{Raquel Aragão Uchôa Fernandes, Maria Lygia Almeida e Silva Koike,}

Michelle Cristina Rufino Maciel, Laura Susana Duque-Arrazola

${ }^{1}$ Dentre os grupos que compõem esta articulação citamos o Mecanismo Estadual de Prevenção e combate à Tortura-MEPCT/PE; Grupo Além das Grades; Ministério Público de Pernambuco; Núcleo de Estudos e Pesquisas sobre a Mulher e o Observatório da Família.

${ }^{2} \mathrm{O}$ projeto de pesquisa em questão está vinculado às ações do Observatório da família, criado em 2011, e que tem o propósito de ser uma organização de pesquisa, produção de conhecimentos, metodologias, compartilhamento de informações e proposições políticas no campo da família e dos direitos humanos.
Portanto é fácil compreender que estas mulheres são muito mais vítimas do oportunismo dos grandes traficantes que, percebendo as fragilidades financeira, familiar e social, as recrutam para expandir o seu comércio ilícito.

Por isso é importantíssimo uma análise menos dogmática por parte do poder judiciário e dos demais operadores do direito, tendo em vista que a aplicação da lei penal das drogas parece, a muitos analistas do cárcere, sexista e misógina, pois penaliza duplamente a mulher que se envolve com o tráfico que, ao ser presa é presa (em um sistema penal historicamente pensado para prender homens), deixa os filhos desamparados afetiva e financeiramente, uma vez que o envolvimento com este ilícito penal é muitas vezes motivado por necessidade de prover economicamente suas unidades familiares.

Para as mulheres encarceradas, a suspensão do direito à liberdade faz com que estabeleçam diferentes táticas para garantir no cotidiano o atendimento às necessidades básicas de sobrevivência, bem como para o não rompimento de vínculos sociais e familiares, sobretudo no que diz respeito às questões relacionadas à maternidade. Nesses termos é importante destacar que o crescente número de mulheres sendo encarceradas mundialmente representa quase que igual percentual de mães ou cuidadoras primárias das crianças vivendo o cárcere. Neste sentido, segundo Taylor (2004), isto significa que o aprisionamento feminino não pode ser considerado isoladamente, devido às implicações sobre a família e seus dependentes, além de que, nos casos mais graves, poderá ter consequências para a sociedade em geral (TAYLOR 2004, p.24 apud MELO, 2014, p.07).

Essa realidade provoca reflexões em torno da maternidade vivenciada durante o período de aprisionamento, pois, a detenção pode ocasionar implicações negativas à mulher e também às crianças, como no caso de uma gestação, com possíveis efeitos à gravidez ou à criança que está sendo gerada. "Deve-se considerar que a gestação gera diversas alterações biopsicossociais na vida da mulher, aumentando a probabilidade de haver prejuízos em virtude do aprisionamento" (MELO, 2014, p.09)

Diante do exposto, o presente trabalho tem por objetivo identificar as marcas de subalternidade do cotidiano das mulheres em situação de privação de liberdade no Estado de Pernambuco e seus desdobramentos para o exercício da maternidade. Buscamos compreender o cotidiano de mulheres que vivenciaram ou vivenciam o cárcere, com destaque para as questões relacionadas às trajetórias de vida, subjetividade e consumo (acesso a bens e serviços).

A presente pesquisa se caracterizou pelo seu caráter qualitativo e tomou como referência o estudo de caso do cárcere feminino em Pernambuco, subsidiado pela realização de grupos focais, com pesquisadores/as e profissionais com alguma atuação no universo do cárcere ${ }^{1}$. No primeiro momento, foi realizado um seminário com a temática de encarceramento e maternidade, promovido pelo Observatório da Família ${ }^{2}$. Esse momento favoreceu diversas problematizações sobre o tema, sobretudo no que concerne 
os primeiros contatos com pesquisadores/as e profissionais vinculados ao sistema prisional no estado de Pernambuco. Após a realização do seminário, foi realizada uma mobilização nas redes sociais e outras estratégias em meio digital para formação dos grupos focais.

Os grupos focais foram realizados em três ocasiões: na primeira, além da chamada digital, foram enviados convites para os/as participantes do seminário supracitado. Participaram de cada grupo, em média, 12 pessoas, e ainda uma equipe formada por 5 a 6 relatores. Os grupos tiveram em média 4 horas de duração e deram origem a um grupo de trabalho intitulado Mulheres e o Cárcere. O referido grupo organizou outros três debates públicos referentes ao universo maternidade e cárcere, e já discute propostas de pesquisa e intervenção conjuntas neste campo.

\section{As mulheres e o sistema penitenciário}

O sistema penitenciário brasileiro apresenta historicamente vários problemas. De um lado, esses problemas têm vinculação com o fenômeno do encarceramento em massa, que impede ou limita a possibilidade de o Estado atingir o objetivo anunciado de ressocialização dos indivíduos. De outro, a "qualidade da matéria humana" que ocupa o cárcere - pobres, negros, periféricos, "cidadãos de segunda classe", ou a Ralé, como diria Jessé Souza que não alimenta maiores esforços por parte das classes dominantes de reestruturar a situação do cárcere ou do encarceramento.
De acordo com Daniel Moura (2017), as maiores dificuldades do sistema prisional têm origem na ordem estrutural e socioeconômica do Brasil. A exclusão social desde o final do século XX tem um caráter conceitual que denuncia a ruptura do Estado com o bem-estar social, com o agravante, no caso brasileiro, de este não ter sido amplamente caracterizado. A invisibilidade das diferentes trajetórias destes/as sujeitos, em meio a condições carcerárias muitas vezes insalubres, apresenta-se como limitador à garantia de outros direitos, como à saúde, à educação, à convivência familiar, ao trabalho e acessibilidade, dentre outros.

Neste sentido, compreendemos que parte dos limites do sistema prisional é resultante dos limites da sociedade de modo geral, condição que, por vias transversas, favorece o cometimento de crimes, embora isto não possa se traduzir como regra, apesar de ser constatado a partir da realidade vivenciada pelos/as encarcerados/as, população marginalizada quanto aos direitos sociais, que fazem e refazem os caminhos para a prisão.

Ainda de acordo com Moura (2017), estes indivíduos geralmente são oriundos de camadas sociais mais baixas, mais vulneráveis principalmente à ausência de recursos. A privação de liberdade deveria representar o último ponto a ser perseguido pelo Estado. Este deveria optar pela ampliação de condições dignas de vida para a população - o que aparentemente é visto como custo muito elevado, por implicar um Estado maior e responsável pela efetiva garantia dos direitos fundamentais de mulheres, homens e 
suas famílias, o que tende a ser muito agravado no contexto de redução e desmonte do Estado em curso atualmente

A maior parte das penitenciárias brasileiras (ainda) é formada por excesso de gente, grades e de muros, espaço reduzido e com descompasso enorme entre o número de presos/as e os demais profissionais que atuam neste universo, a citar o efetivo policial e outros profissionais que atuam de modo mais direto no campo da educação e da garantia de não dessocialização completa desses indivíduos, assim como da garantia de acesso aos outros direitos.

A pessoa privada de liberdade, o/a recluso/a, não está, portanto, fora do direito, pois sua relação jurídica em face ao Estado é referente ao ato cometido e, exceto no caso dos direitos (suspensos) perdidos e limitados por sua condenação, sua condição jurídica é igual à das pessoas não condenadas (MOURA, 2017).

De acordo com René Dotti (2003), diante deste cenário a crise carcerária é antiga e determinada, basicamente, pela carência de estruturas humanas e materiais, o que tem dado origem a um outro fenômeno, o da "vitimidade de massa". Ao afirmarmos que a principal finalidade do sistema prisional deve ser a reabilitação do/da preso/a, como dispõe a Lei de Execução Penal - LEP $n^{\circ}$ 7.210/1984, vemos um contrassenso com este sistema que como principal medida "captura", tira a pessoa do convívio social. Parte, portanto, da dessocialização, colocando-a, a partir da privação da liberdade, em contato quase que restrito com o que o Estado tem condições de oferecer, o que historicamente tem sido muito pouco.
Ao partilharem o cotidiano, os indivíduos privados de liberdade fazem daquele espaço e daquelas condições físicas e sociais o seu espaço imediato de socialização, estabelecendo relações societárias algumas vezes próprias e características do ambiente prisional, as quais tendem a provocar mudanças significativas na sua dinâmica cotidiana de vida, isto tanto no caso de homens quanto de mulheres. Esta realidade é apontada por Clemmer, citado por Godoi (2010), quando afirma que um indivíduo, ao passar por uma penitenciária, torna-se suscetível a uma reinterpretação geral da vida.

Nesse processo, novos significados são atribuídos a noções fundamentais que passam a organizar o cotidiano do detento/a, como, por exemplo, a relação com o abrigo, o vestuário, a alimentação, a sexualidade, o trabalho, entre outros elementos fundamentais da vida cotidiana na prisão, que "invariavelmente passam a ser administrados por outrem”, ou seja, passam a apresentar outras significações.

O referido autor aponta ainda:

[...] os fatores universais que caracterizam o processo de prisionização, como um catálogo dos principais efeitos sobre o indivíduo preso, que são: a aceitação de uma posição social inferior; progressiva acumulação na memória de fatos concernentes à organização prisional; desenvolvimento de novos hábitos alimentação, vestuário e sono; adoção de linguagem local; o reconhecimento de que as necessidades fundamentais não podem ser satisfeitas no devido ambiente; e o desejo de conseguir um bom trabalho no interior do presídio (CLEMMER apud GODOI, 2010, p.27). 


\section{Raquel Aragão Uchôa Fernandes, Maria Lygia Almeida e Silva Koike,}

Michelle Cristina Rufino Maciel, Laura Susana Duque-Arrazola

${ }^{3}$ No mesmo sentido alerta o MEPCT/PE quando da produção do Relatório Temático 2016: Um olhar sobre o encarceramento feminino. Recife, 2016
Esse contexto é revelador de uma grande demanda de intervenção por parte das políticas públicas para que garantam minimamente melhores condições de vida à população carcerária, principalmente ao considerarmos a representação dos grupos mais vulneráveis, como é o caso das mulheres, das pessoas idosas, com deficiência e do grupo Lésbicas Gays Bissexuais e Travestis (LGBT).

De acordo com García (1998), a prisão para a mulher é um espaço discriminador e opressivo, que se expressa na aberta desigualdade do tratamento que recebe, no sentido diferente que a prisão tem para ela, nas consequências para sua família, na forma como o Poder Judiciário reage em face do desvio feminino e na concepção que a sociedade atribui aos desvios. Por isso, a prisão estigmatiza mais as mulheres do que os homens.

[...] as presas mulheres tendem a sofrer física e mentalmente em graus e com severidade que excedem, de longe, os presos. Isso pode estar relacionado às razões pelas quais foram encarceradas, como, por exemplo, condenações por condutas praticadas em reação a um contexto de violência reiterada [que supostamente deveria ser suportado] (JOANEBELKNAP apud MEIRELLES, 2006, p. 163)

A Constituição Federal de 1988 estabelece que homens e mulheres são iguais perante a lei. Sob esta justificativa, as leis invizibilizam as mulheres e, quando se referem às pessoas privadas de liberdade, fazem referência quase que exclusivamente ao gênero masculino, a exemplo da Lei de Execução Penal-LEP, que se utiliza das palavras "condenado", "interno", "recluso". A Assembléia Geral da Organização das Nações Unidas, ONU, adotou no ano de 1948 a Declaração Universal de Direitos Humanos, iniciando o sistema global de proteção aos Direitos Humanos, cujos destinatários são todos os seres humanos, em sua abstração e generalidade (PIOVESAN, 2003).

Do processo de especificação dos sujeitos de direitos, resultaram tratados internacionais relativos a temas e grupos específicos. Entre as principais convenções da ONU, que constituem parâmetros mínimos das ações estatais na promoção dos Direitos Humanos e na repressão às suas violações está a Convenção Internacional para a Eliminação de todas as Formas de Discriminação contra a Mulher (CEDAW, sua sigla em inglês).

Esse cenário, no entanto, é apresentado pelo seu inverso. A situação das unidades prisionais femininas brasileiras é alarmante ${ }^{3}$. Conforme o relatório sobre a Reorganização e Reformulação do Sistema Prisional Feminino no Brasil, "as mulheres detidas no país são submetidas a graves violações de direitos, reproduzindo o mesmo desamparo experimentado pelos homens presos" (BRASIL, 2008, p. 169).

Os dados oficiais nacionais sobre a situação das mulheres privadas de liberdade apresentam lacunas no que concerne às diferentes realidades. Entre os estudos e pesquisas que têm sido desenvolvidos sobre o tema no país, os dados apontam que a grande maioria das mulheres encarceradas "são jovens, mães solteiras, afrodescendentes e, na maioria dos casos, condenadas por 
envolvimento com tráfico de drogas (ou entorpecentes)" (BRASIL, 2008, p. 127).

As mulheres, ao serem privadas de liberdade, são privadas de vários outros direitos, que de alguma forma garantiriam a integridade de sua dignidade e auto-imagem, ainda que sob a tutela do Estado. São privadas do direito à intimidade, à privacidade, à saúde, inclusive sexual e reprodutiva-, à segurança pessoal. Entre os inúmeros direitos que as mulheres presas cotidianamente têm violados, se destacam, especialmente, o direito de viver livre de discriminação e de violência, que deveria ser respeitado sem restrição, uma vez que estão sob a total tutela do Estado.

Em relação ao comportamento, o que o quadro técnico do Sistema Prisional -formado por psicólogos, assistentes sociais e médicos - tem constatado é que, quanto mais avançada a idade da pessoa aprisionada, maiores serão a passividade, a incidência de depressão, o cansaço, a decadência física, os problemas de saúde, o abandono, a ausência de visitas, o isolamento voluntário, a falta de perspectiva, a abnegação e a tolerância.

No caso da saúde, é importante lidar com o que está previsto, e ainda não implementado adequadamente no Plano Nacional de Saúde no Sistema Penitenciário de 2003, elaborado através de uma parceria entre os Ministérios da Saúde e da Justiça, com o objetivo de organizar o acesso das populações privadas de liberdade às ações e serviços de saúde do Sistema Único de Saúde (SUS) de forma integral. O tamanho do desafio é proporcional à precariedade existente. E, embora date de 2003, constituiu-se como intenção, visto que o cenário ainda é de condições insalubres das cadeias, o que se repete em todos os estados.

Fazer o enfrentamento desta realidade é urgente. E um dos caminhos é reconhecer quem é efetivamente este público, qual a sua trajetória, suas especificidades, para a possível articulação com outras políticas e programas, que não podem ficar restritos aos muros das cadeias e penitenciárias. É preciso reivindicar a melhoria das condições de vida e saúde das mulheres privadas de liberdade, mediante a garantia de direitos legalmente constituídos, a citar os apresentados no referido Plano. Há incorporado ao Plano a responsabilidade de estruturação de unidades básicas de saúde nos estabelecimentos prisionais, necessidade da definição de fluxo de referência e contra-referência para as unidades que compõem as redes relativas aos demais níveis de atenção, garantindo a consonância da política com os princípios de integralidade e resolutividade (BRASIL, 2008, p. 62).

Entre as ações específicas, estão a realização de pré-natal, controle do câncer cérvico-uterino e de mama, com as seguintes metas: implantação, em $100 \%$ das unidades penitenciárias, de ações para detecção precoce do câncer cérvico-uterino e de mama; implantação, em 100\% das unidades penitenciárias, de ações para diagnóstico e tratamento das DST/AIDS; implantação, em 100\% das unidades penitenciárias, da assistência à anticoncepção; implantação, em 100\% das unidades penitenciárias que atendem à população feminina, da assistência ao pré-natal de baixo e alto risco no primeiro ano do Plano; implantação da imunização das gestantes 
${ }^{4}$ Vulnerabilidade refere-se a estado de pessoas ou grupos que, por quaisquer razões ou motivos, tenham a sua capacidade de autodeterminação reduzida (VIEIRA e OLIVEIRA, 2011, p. 3) em 100\% das unidades penitenciárias; implantação de assistência ao puerpério em $100 \%$ das unidades penitenciárias; implantação, em $100 \%$ das unidades penitenciárias, de ações educativas sobre prénatal, parto, puerpério, anticoncepção, controle do câncer cérvicouterino e de mama e doenças sexualmente transmissíveis; garantia do encaminhamento para tratamento das mulheres com câncer cérvico-uterino e de mama atendidas em $100 \%$ das unidades penitenciárias; garantia do acesso das gestantes, em 100\% das unidades penitenciárias, ao atendimento de intercorrências e partos (BRASIL, 2008, p. 63).

A vulnerabilidade a que as mulheres estão expostas no sistema prisional é multidimensional e pode ser observada de diferentes ângulos ${ }^{4}$. Segundo Ayres e outros autores (1999), a vulnerabilidade social leva em conta as condições sociais da população, acesso à informação e serviços de saúde, indicadores epidemiológicos, aspectos sociopolíticos e culturais, grau de liberdade de pensamento e expressão dos diferentes sujeitos, condições de moradia, nível de escolarização, oferta de trabalho, distribuição de renda, entre vários outros fatores que, para a compreensão da vulnerabilidade a que está sujeito o indivíduo, devem ser analisados de modo articulado.

De acordo com o estudo realizado por Borges (2002), quando a mulher é presa as crianças são distribuídas entre avós, vizinhas ou encaminhadas a órgãos de assistência social. Ainda de acordo com a autora, o preso homem recebe visitas de sua esposa, companheira ou namorada, a família não lhe nega apoio, e a mulher presa, no início recebe visitas, que passam a rarear, até a sua definitiva interrupção. As dificuldades adicionais impostas às mulheres ao exercício dos direitos sexuais, reprodutivos e à convivência familiar constituem alguns exemplos da aplicação desigual da LEP.

Lembre-se que mais situações podem ser identificadas porque decorrem da desigualdade real entre homens e mulheres: a desigualdade, o preconceito e a discriminação presentes extra muros se reproduzem intra muros. O desvendamento do mundo das mulheres encarceradas em nosso país iniciou com atraso. As pesquisas datam dos anos 1980, e diante do processo de criminalização crescente das mulheres, observa-se o problema da execução das penas privativas de liberdade, aplicadas a elas, atentatória à sua integridade física e moral. A regra geral de que o preso conserva todos os direitos não atingidos pela perda da liberdade tem sido insuficiente para assegurar o respeito a esses direitos para os homens e, mais ainda, para as mulheres (CASTILHO, 2008).

No caso do grupo de mulheres lésbicas e/ou bissexuais, e transexuais, a condição de vulnerabilidade dentro do sistema prisional está associada à marca do preconceito devido à orientação sexual “consideradas em 'desconformes' no interior de uma sociedade tipicamente heterossexista". No cotidiano dentro das unidades o tratamento recebido por outras mulheres e até mesmo por funcionários/as das unidades revelam uma série de preconceitos, assim como o enfraquecimento ou rompimento dos vínculos com a família tende, como já mencionamos, a ser maior neste grupo. A 
homofobia e a transfobia dentro das penitenciárias, atinge diretamente a dignidade destas mulheres fazendo-as sofrer duplamente, primeiro pela ausência de liberdade, segundo, pelos percalços que enfrentam em decorrência do desrespeito (VIEIRA e OLIVEIRA, 2011).

Assim sendo, não há que se admitir que a saúde sexual e reprodutiva da mulher no sistema prisional não faça parte das ações necessárias ao atendimento integral. Há que se garantir às mulheres privadas de liberdade o fornecimento de produtos mínimos de higiene, como papel higiênico e absorvente íntimo, além de preservativos femininos, como medida preventiva e de garantia de Direitos Humanos. Tal proposta deve ser aliada à estruturação de cursos e palestras às presas sobre doenças sexualmente transmissíveis e educação sexual, abrangendo direitos sexuais e reprodutivos e a liberdade de opção sexual. Referidos cursos não devem ser ministrados apenas às mulheres encarceradas, mas também às suas famílias e demais envolvidos/as em suas histórias de vida; bem como aos agentes penitenciários (BRASIL, 2008, p. 64).

A compreensão do direito à igualdade a partir deste campo é tarefa para a reflexão sobre direitos humanos e identidade. Compreender-se enquanto como sujeito de direitos é urgente às pessoas em cárcere e deve ser tomado como demanda fundamental, do mesmo modo que discutir com a comunidade carcerária as especificidades deste público. Há indícios suficientes de que o Estado necessita tomar medidas urgentes em favor da população
LGBT que se encontra presa, posto haver necessidade constitucional de proteção da integridade destas pessoas (art. $5^{\circ}$, inciso XLIV, da CF/88) (VIEIRA e OLIVEIRA, 2011, p. 9).

Neste sentido a compreensão das trajetórias de vida e das diferentes identidades permite que se compreenda o grau de vulnerabilidade a que cada sujeito e grupo está exposto, a dinâmica de propagação da vulnerabilidade dentro e fora das unidades prisionais, entre outros - caso dos/as pessoas com deficiência ou mobilidade reduzida, portadoras de necessidades especiais, inviabilizadas e colocadas em condição ampliada de privação de direitos por falta de uma estrutura física e social que dê conta de suas especificidades. Essa situação se repete com pessoas idosas e com os/as que, heterossexuais ou não, configurem "título" de menor força - como boa educação, tez ou pele delicada, timidez, medo, compleição, fragilidade e etc. - que passam a ser tidos como homossexuais, e a receber tratamentos discriminatórios (VIEIRA e OLIVEIRA, 2011, p. 9).

No entanto é preciso considerar a importância do apoio e sororidade vivenciado por estas mulheres, o que pode, em alguns casos, se transformar em relações homoafetivas, como forma de conseguir vivenciar cuidado, afetividade.

[...] Aparecimento de cuidados como beijo, abraço, preocupação com banho, higiene, o dia de visitas e a importância com a limpeza do ambiente. Aqui em Pernambuco ocorre a livre manifestação dos afetos, diferentemente de outros estados. Observamos a existência de 
pequenos conflitos cotidianos, e as formas como estes podem ser administrados: presença de companheirismo nos dias de visita, pessoas de companheirismo nos dias de visita, pessoas de
outros estados que não são visitadas. Existe uma solidariedade entre elas, quem são, quais suas histórias. (Grupo focal 2)

O Estado, quando condena uma pessoa que cometeu um crime contra a sociedade e por conseqüência aplica a essa uma pena restritiva da liberdade, teoricamente acredita que, após o cumprimento da sentença expedida, esse indivíduo estará apto ao convívio social, ou seja, ressocializado. No entanto, essa "reeducação" que objetiva o Estado na prática não existe. Primeiro porque o que tem sido a principal preocupação do sistema penitenciário ao receber uma pessoa condenada não é sua reeducação, mas sim a privação de sua liberdade. Isso é fácil de ser constatado na medida em que analisamos as estruturas da maioria das penitenciárias brasileiras, formadas por excesso de grades, muros enormes e baixo efetivo policial. Tudo isso tem um único objetivo, evitar a fuga.

No campo do direito à convivência familiar, aponta Lemgruber (2010, p. 83) que, para a mulher, "o rompimento do contato contínuo com seus familiares e, sobretudo, seus filhos, afigura-se-Ihe extremamente difícil de suportar”. As condenações longas provocam, em geral, o rompimento da união conjugal. Segundo a autora (LEMBGRUBER, 2010, p. 105), há "vários casos de mulheres que tendo oportunidade de receber a visita do namorado suspendiam suas atividades homossexuais". Segundo a mesma, dentro do sistema, a tolerância em relação às convivências homoafetivas tende a ser reduzida, sob a justificativa de que as relações homossexuais provocam muitas brigas. Esta perspectiva é polêmica, e o inverso também é possível constatar. No caso de mulheres chefes de família, os efeitos em relação aos filhos e para ela própria é devastador.

Neste artigo nos interessa identificar as marcas de subalternidade do cotidiano das mulheres em situação de privação de liberdade no Estado de Pernambuco e seus desdobramentos para o exercício da maternidade. Buscamos compreender o cotidiano de mulheres que vivenciaram ou vivenciam o cárcere, com destaque para as questões relacionadas às trajetórias de vida, subjetividade e consumo (acesso a bens e serviços).

\section{Mulheres, gestantes, mães: a vida no cárcere}

Como se não bastasse o arsenal de violação de direitos vivenciados pelas mulheres encarceradas, existem situações que se agravam, caso das mulheres gestantes e/ou com filhos/as pequenos na prisão. Uma série de fatores tem contribuído para efetivação expressa de violações de direitos ligados ao que diz o texto constitucional de 1988, em art. 5º, inciso XLV, quando este recomenda que nenhuma pena passará da pessoa do condenado (BRASIL, 1988), mas, no caso da gestação ou do nascimento no cárcere, as penas passam, em alguma medida, das mulheres para as crianças. 
${ }^{5}$ A redação do referido artigo passou a ser: "Art.318. Poderá o juiz substituir a prisão preventiva pela domiciliar quando o agente for: $[\ldots]$ IV - gestante; V - mulher com filho de até 12 (doze) anos de idade incompletos.
Os casos em que as mulheres são encarceradas grávidas ocorrem com grande frequência, e a elas deveriam ser destinados cuidados especiais, como determinam regramentos internos e internacionais, em especial quanto à assistência médica (BRASIL, 2014). Entretanto a realidade vivenciada pelas mulheres encarceradas não se revela de modo simples.

No Relatório sobre Mulheres Encarceradas no Brasil (BRASIL, 2007, p. 32), consta que as falhas do Estado começam nos cuidados de pré-natal, pois a maioria das mulheres não realiza nenhum tipo de exame de laboratório ou mesmo de imagem, o que acarreta grave ameaça à vida e à saúde de mãe e filho. Estes procedimentos são necessários para garantir que a gravidez ocorra de forma o mínimo saudável, haja vista que uma gravidez em ambientes carcerários por si só já configura alto risco.

A mulher gestante ou lactante não está numa situação comum. Seu corpo passa por sérias variações hormonais e fisiológicas. Em termos práticos, essas questões não são levadas em conta, embora exista uma legislação que protege as mulheres que estão nesta situação. Para exemplificar esta questão podemos citar o art. 318, inciso IV do Código de Processo Penal - CPP, que diz: "Poderá o juiz substituir a prisão preventiva pela domiciliar quando o agente for: V- gestante" (BRASIL, 1941). E ainda o art. 117, inciso IV, da LEP: "Somente se admitirá o recolhimento do beneficiário do regime aberto em residência particular quando se tratar de: condenada gestante" (BRASIL, 1984).
Parece salutar chamar atenção para a Lei $\mathrm{n}^{\circ} 13.257$, de 08 de março de 2016, também conhecida como Marco Legal da Primeira Infância, que veio alterar a redação do art.318 do $\mathrm{CPP}^{5}$. Esta alteração permitiria às gestantes que sua prisão preventiva fosse convertida em prisão domiciliar, sem fazer distinção do tempo gestacional uma vez que, na redação antiga, o art. 318 do CPP determinava que o beneficio da prisão domiciliar apenas seria concedido às gestantes a partir do sétimo mês de gravidez ou em casos de gravidez com risco de vida ao feto/mãe. Desta forma, não se exige mais que haja um tempo mínimo de gestação ou o risco de vida para que se conceda tal beneficio (BRASIL, 2016). No entanto têm-se percebido resistência por parte dos magistrados em relação a este entendimento.

O Marco Legal da Primeira Infância não versa somente sobre filhos de mulheres que estão encarceradas. Em verdade, ele é uma política que traz como fulcro a proteção a todas as crianças do país e, neste universo, incluem-se as mães que estão sob a guarda do Estado. O sujeito detentor de direitos é a criança, e não a presa, ainda que esta seja mãe. A lei reconheceu o risco ao qual as crianças e fetos estão submetidos em caso de encarceramento de suas mães, pois o encarceramento pode submetê-las a risco de morte e algo assim afeta permanentemente o desenvolvimento psicossocial de uma criança e ainda promove um distanciamento entre mães e filhos, o que gera uma situação de frágil socialização para estes (FARIAS, 2017) 


\section{Raquel Aragão Uchôa Fernandes, Maria Lygia Almeida e Silva Koike,}

Michelle Cristina Rufino Maciel, Laura Susana Duque-Arrazola

${ }^{6}$ www.stf.jus.br/portal/processo/verProce ssoAndamento.asp?numero $=143641 \& c l$ $\mathrm{sse}=\mathrm{HC} \&$ origem $=\mathrm{AP} \&$ recurso $=0 \& \mathrm{t}$ poJulgamentocias.
Recentemente o país todo pôde acompanhar por meio da impressa uma decisão tomada pelo ministro Gilmar Mendes, no processo de Adriana Ancelmo, esposa do ex-governador do Rio de Janeiro, Sergio Cabral. Adriana Ancelmo foi condenada a 18 anos e 3 meses de prisão por lavagem de dinheiro e participação no esquema de corrupção comandado pelo marido. A ré possui dois filhos, um de 11 e outro de 14 anos e, desta forma, enquadra-se a receber os benefícios da Lei 13.257/2016. Em sua decisão o magistrado alegou que:

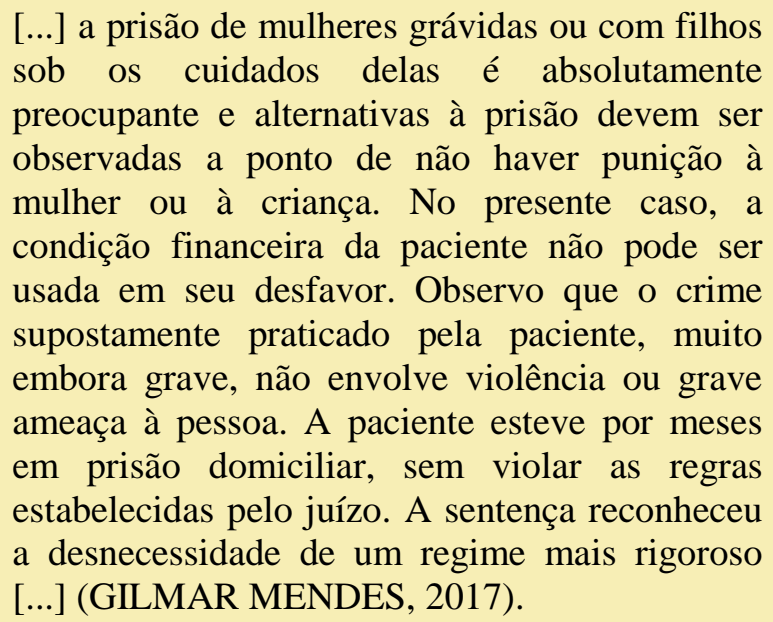

Contudo, a decisão neste caso concreto é rara no direito brasileiro: o que há, em verdade, é a manutenção das prisões preventivas de mulheres grávidas ou mães sob o argumento de que a presa que solicita o benefício da prisão domiciliar por vezes não preenche as condições para tal, pois tem envolvimento com tráfico de drogas.
A decisão, no caso de Adriana Ancelmo, lançou luz ao Habeas Corpus (HC) 143.641, impetrado pela Defensoria Pública da União (DPU) e pelo Coletivo de Advogados em Direitos Humanos (CADHU), em 08 de maio de 2017, que pretendeu converter em prisões domiciliares as prisões preventivas de "todas as mulheres submetidas à prisão cautelar no sistema penitenciário nacional, que ostentem a condição de gestantes, de puérperas ou de mães com crianças até 12 anos de idade sob sua responsabilidade, e das próprias crianças"6 (PAZ, et al, 2017), que estejam em condições para tal. Em 20 de fevereiro de 2018, a Segunda Turma do Supremo Tribunal Federal julgou:

[...] por maioria de votos, conceder habeas corpus (HC 143641) coletivo para determinar a substituição da prisão preventiva por domiciliar de mulheres presas em todo o território nacional, que sejam gestantes ou mães de crianças de até 12 anos ou de pessoas com deficiência, sem prejuízo da aplicação das medidas alternativas previstas no artigo 319 do Código de Processo Penal (CPP).” (BRASIL, 2018).

A decisão do STF representa um marco importante no enfrentamento às constantes violências que ocorrem no sistema prisional e também permite uma correção no tratamento desigual que é dispensado às mulheres encarceradas.

O HC 143.641 expôs de forma clara a seletividade do sistema de justiça criminal brasileira, pois seu julgamento nos mostra que os benefícios da lei antes eram destinados a poucas mulheres e tendem a contribuir para a diminuição da superlotação nos presídios. No caso deste estudo, discussões em torno do tema têm sinalizado que 
cerca de $50 \%$ das mulheres que hoje estão em situação de privação de liberdade poderiam aguardar seus julgamentos em liberdade e, com isto, assegura-se também o direito das crianças ao convívio com suas mães em seus primeiros anos de vida, algo que é vital para o desenvolvimento psicossocial.

\section{Perfil das mulheres encarceradas no Estado de}

\section{Pernambuco}

No Estado de Pernambuco, o perfil das mulheres encarceradas não se difere do perfil dos demais Estados brasileiros, de modo que as unidades prisionais contam com maioria de mulheres negras ou pardas, jovens, com baixa escolaridade e que têm filhos, cuja origem são as camadas menos abastadas da sociedade e que, em sua maioria,exerciam atividades informais de trabalho antes de adentrarem o sistema prisional (BRASIL, 2018).

No que se refere ao perfil de idade das mulheres em situação de cárcere em Pernambuco, os dados mostram que 51\% tem idade entre 18 e 34 anos, $44 \%$ tem idade entre 35 e 60 anos e apenas 5\% tem idade superior a 60 anos (BRASIL, 2018). Para a maioria destas mulheres, o envolvimento com tráfico de drogas ou furtos significou o envolvimento com o mundo do crime. Considerando esse contexto, podemos constatar que a trajetória de vida das mulheres em situação de privação de liberdade é seletiva, na medida em que "o narcotráfico e o consumo de drogas não são exclusivos das classes mais pobres, só que estas, pelo seu baixo poder de manobra frente ao Sistema de Justiça Criminal - SJC, serão mais punidas que as classes mais ricas" (POSADA, et al, p. 288).

Nessa perspectiva, dados da Infopen (2018) também destacam que a maioria das mulheres encarceradas pelo envolvimento com tráfico de drogas e participação no mundo do crime se dá de forma secundária. Elas exercem, sobremaneira, transporte ou venda de drogas e são, em muitos casos, usuárias. Além dessas situações mencionadas, os depoimentos chamam atenção para o envolvimento com o tráfico mediante vínculo afetivo com seus companheiros.

\section{A vida real: o tempo no cárcere}

No estado de PE existem as Colônias Penais Femininas de Abreu e Lima - CPFAL, Buíque -CPFB e do Recife - CPFR, e há também o Hospital de Custódia e Tratamento - HCTP, que abriga pessoas com problemas mentais que cometeram delitos e é unidade prisional mista. A CPFB e a CPFR são unidades exclusivamente femininas, enquanto as demais são unidades mistas. A maior parte da população carcerária feminina é majoritariamente urbana e se distribui da seguinte forma: 44,85\% na CPFR;33,95\% na CPFAL; 19,79\% na CPFB; e 1,40\% no HCTP (FERREIRA, 2017).

Quando confrontamos o número de vagas para detentas que existe no sistema prisional de Pernambuco, que é de aproximadamente 600 vagas (UGIETTE, 2018), ao número de mulheres que está no sistema, aproximadamente 1500 , fica evidente 
a situação de superlotação das principais unidades prisionais do Estado.

Além da questão da superlotação, que interfere diretamente nas condições de vida das mulheres encarceradas, estas têm necessidades específicas e a estrutura das unidades prisionais que estão em cumprimento de pena não são adequadas para o atendimento das necessidades femininas, uma vez que os presídios foram planejados por homens para homens "guardarem" outros homens e, com isto, as necessidades das mulheres foram esquecidas na elaboração destes espaços.

Mesmo problematizando essa realidade, as mulheres que se encontram cumprindo pena restritiva de liberdade, ou mesmo esperando julgamento, são obrigadas a se expor a prédios públicos inadequados para seu acolhimento. Nesse sentido, as mulheres aprisionadas não têm ambientes que sirvam adequadamente para tal fim. Podemos dizer que o encarceramento feminino é realizado de forma extremamente improvisada. Tal qual nos presídios que abrigam homens, as mulheres também sofrem com problemas como superlotação, falta de saneamento básico nas unidades prisionais, alimentação de má qualidade e ausência de água (CERNEKA, 2009; COLARES; CHIES, 2010), entre outras formas de violação de direitos fundamentais para a garantia de uma convivência digna dentro das unidades prisionais.

Nesse sentido, a cobertura de saúde existente, que é um item fundamental para a garantia dos Direitos Humanos, nas unidades prisionais femininas do Estado de Pernambuco não atende plenamente às reeducandas e apresenta algumas diferenças entre as unidades: em algumas unidades, existe coleta de sangue semanal na própria Unidade prisional e realização semanal de exames preventivos (SANTA CRUZ et al, 2017, p.11); em outras, o atendimento pode ser muito parcial ou até mesmo inexistente. Sobre a unidade prisional do Recife, "a Colônia tem uma ambulância, porém está em péssimo estado. A unidade também, à data da visita, estava sem pediatra. Na equipe técnica de saúde há duas enfermeiras e um dentista; o médico lotado na unidade estava afastado" (MONTEIRO, 2017, p. 25).

Mesmo que o acesso à saúde não seja de todo negligenciado, são necessárias ações mais efetivas para que as mulheres encarceradas tenham seu direito à saúde totalmente atendido, uma vez que estão sob a guarda do Estado. Na CPFAL, segundo Monteiro (2017), as internas têm dificuldade na marcação de consultas médicas, pois a rede municipal de saúde em Abreu e Lima não as acolhe, e ainda "a rede de saúde de Recife não acolhe também essa população, tendo em vista estarem em outro município" (MONTEIRO, 2017, p.24). Há o registro também de "ausência de profissionais de saúde na área de psiquiatria, ginecologia e enfermagem na unidade. A falta de psiquiatra gera uma série de violações de direitos humanos às mulheres que apresentam indícios de transtornos mentais" (SANTA CRUZ et al, 2017, p. 15).

Na unidade de Buíque, as reeducandas "realizam consultas e exames de ingresso. Há um local apropriado para exame 
ginecológico e para medir a pressão arterial, passando pelo médico, odontólogo e pela psicóloga, conforme determinação das Regras de Bangkok" (SANTA CRUZ et al, 2017, p.27).

Dados do Relatório Sobre Mulheres Encarceradas no Brasil (2007, p. 27) demonstram que o acesso a profissionais de saúde é precário ou mesmo inexistente e isso tem impacto direto na saúde da mulher que passa à condição de encarceramento, tenha ela algum problema de saúde no momento do ingresso ou venha a adquiri-lo em seu interior (GRECO, 2010, p. 268).

Ademais, a falta de assistência médica também se traduz na falta de medicamentos, seja um simples analgésico ou remédios mais complexos. Tal situação compromete a eficácia de tratamentos médicos, como é o caso de tratamentos antidepressivos, uma vez que o adoecimento psiquico e o consumo de substâncias psicoativas é uma realidade nas prisões. Segundo o relatório supracitado, nos 17 estados pesquisados no Brasil, 08 afirmaram que presas fazem uso de medicação controlada (2007, p.31), e a insuficiência destes medicamentos tem implicado em problemas, tais como o suicídio.

No que diz respeito vivência da maternidade no cárcere , em Pernambuco as Colônias Penais que possuem berçário são as unidades de Buíque e do Recife; as demais unidades prisionais do Estado não contam com tal estrutura.

Segundo Koike (2017), foi na CPFR que foi implantado o primeiro berçário em unidades prisionais do Estado de Pernambuco e "cada bebê tem sua banheira e seus pertences organizados pelas mães. No espaço havia ainda disponível uma televisão, um sofá bastante usado e um bebedouro" (KOIKE, 2017, p.32). Dados do Ministério Público de Pernambuco (MPPE) dão conta que, em abril de 2018, o número de reeducandas da CPFR que estavam gestantes eram 11, e o berçário estava ocupado por 4 bebês e suas respectivas mães.

Na unidade de Buíque, o berçário é um espaço adaptado, "composto por dois quartos com camas individuais e banheiros, cada um tem uma janela grande. Não foram encontrados berços para os bebês; eles dormem junto com suas mães e não há um espaço específico destinado para o banho de sol das crianças" (KOIKE, 2017, p.33). Dados do MPPE dão conta de que, na CPFB, em abril do ano corrente o número de mulheres gestantes era de 5 , e o número de crianças no berçário era de 4 juntamente com suas respectivas mães.

[...] As mulheres chegam grávidas ao cárcere e lá têm de ter seus filhos. Em Buique todas chegaram grávidas. Existem casos de mulheres que são torturadas... tortura psicológica. Uma mulher menstruou e não permitiram que ela se lavasse, humilhação sofrida por uma condição normal e orgânica!! Presença de muitas mulheres masculinizadas, forma de defesa às agressões que sofrem. (Grupo focal)

[...] O boi!!! "privada", uma grávida tem certas necessidades que não são observadas quando de seu encarceramento, necessidades fisiológicas. Não existe planejamento: pegaram o sistema masculino e o impuseram ao feminino (Grupo focal).

[...] Não existe a preocupação com a alimentação de quem tá grávida ou amamentando. Lá em 
Recife eles davam galinha frita pra elas comerem (Grupo focal).

[...] Em Abreu não tem berçário. Quando tem grávida lá, tem que transferir para Recife e isso dá um problema, porque o processo tem sair de uma vara de execução para a outra, senão não pode transferir (Grupo Focal 3).

Os depoimentos apresentam diversas formas de violência física e psicológica, além do descuido com a saúde de mulheres grávidas, fatos que contribuem para a precariedade da permanência das encarceradas nas unidades. Fica evidente também a necessidade de investimento na estrutura física e funcional destes espaços para que possam de fato contribuir para a ressocialização das presas e para que sua estada no sistema prisional do estado não seja mais traumática.

Outra situação que causa inquietação são os casos dos recémnascidos que permanecem com as mães nas unidades prisionais até os seis meses ou até o período da amamentação e depois há a ruptura do vínculo afetivo entre a mãe e o bebê: a grande maioria das crianças são entregues para as famílias das mães presas, mas há outros bebês que são entregues à adoção.

Outra provocação importante a destacar na pesquisa é a realidade do abandono afetivo por parte de seus familiares. Os homens em situação de cárcere por vezes continuam tendo uma vinculação junto às suas famílias, pois recebem visitas de seus familiares, sejam estes esposas e filhos ou mesmo suas mães; já com as mulheres presas de forma geral o mesmo não ocorre (FARIAS, 2017).

Os depoimentos expressam elementos de uma cultura patriarcal, sexista e androcêntrica. Como consequiência desta, as mulheres em condição subalterna tornam-se vulneráveis, seja por suas famílias ou companheiros que as abandonam ou pelo Estado, que se omite e/ou negligencia direitos delas.

A pesquisa também revelou outro fato que merece destaque: a má qualidade da alimentação oferecida para as mulheres. Esse dado se traduz na alimentação que não garante itens adequados para uma alimentação saudável, sobretudo ao compreender especificidades de saúde de cada uma delas. Os dados da pesquisa revelaram que a maior parte das detentas alimentam-se de biscoitos e outros alimentos de baixo valor nutritivo, Monteiro (2017).

[...] Lá dentro tem que ter dinheiro. Se não, nãO tem jeito de consumir, quem está fora leva pra dentro, o que não é tranqüilo, mas elas se ajudam. As famílias passam por todo tipo de constrangimento, quando levam comida. Ela é toda bagunçada pelo pessoal que faz a revista (Grupo focal?).

Percebemos aqui a necessidade que as detentas têm de apoio, e as formas que elas encontram de fazer frente ao sistema para que possam conseguir sobreviver na realidade difícil e desumana a qual estão submetidas. sexualidade. "Você gosta de mulher?" "Claro, 
sou homem", uma me disse. O número de mulheres homossexuais é alto "Eu tô lésbica". Existe a visita íntima nas unidades, todavia o número de mulheres que a recebe de seus "companheiros" é baixíssimo, presença de homens trans e mulheres trans (Grupo focal 2)

O cotidiano dentro de uma unidade prisional feminina se revela difícil, pois direitos básicos e previstos em lei são negados. As mulheres são reduzidas à condição de sub-humanidade, em especial as mulheres negras e lésbicas, que passam por torturas e outras violações. Não existe ressocialização. O Estado não tem responsabilidade social com as internas e está longe de conseguir garanti-la.

\section{CONSIDERAÇÕES FINAIS}

De modo geral a presente pesquisa nos permite apresentar algumas questões que são comuns ao cárcere, e ao encarceramento, a exemplo das vivências cotidianas que permitem a vinculação da reflexão do encarceramento feminino ao grupo a que Jessé Souza (2016) chama provocativamente de Ralé (SOUZA, 2016).

No caso das mulheres desta pesquisa, o endereço periférico acaba por conferir a elas trajetórias bastante similares seja em relação ao Estado, como à sociedade. A precocidade tem sido a marca de muitas destas vidas, seja no que diz respeito ao afastamento, quanto à aproximação: o afastamento precoce da escola e a consequente inserção no mercado de trabalho; a vivência precoce da sexualidade e da maternidade; os sonhos não realizados que ficam pelo caminho; os amores pobres, marcados pela instabilidade e curta duração. São histórias de vida que, em sua singularidade, demonstram o peso de alguns determinantes para a sua repetição - uma espécie de repertório, que é encenado nos diferentes lugares por sujeitos específicos.

Neste sentido, Gayatri Spivak (2010) evoca a responsabilidade que o intelectual tem em desafiar os discursos hegemônicos produzidos (muitas vezes por nós mesmos) sobre os sujeitos subalternos, restabelecendo estes lugares, uma vez que o peso desta supermodernidade é muitas vezes excessivo em termos de desenraizamento para os indivíduos subalternos.

As mulheres com vivência no cárcere no estado de Pernambuco apresentaram trajetórias marcadas por contextos familiares e social provenientes das classes subalternas, os quais estão mais suscetíveis à negação e negligência de direitos sociais. De acordo com Silvia Losacco (2009), tratam-se de trajetórias fortemente marcadas pela necessidade de ganho e entrada precoce no mundo do trabalho, indivíduos que ainda são bastante jovens, na maioria das vezes ainda adolescentes, que são convidados a se inserirem no mundo do trabalho, o que por vezes vem a contribuir para a evasão escolar e/ou pouco rendimento no processo de aprendizagem na escola, fatores determinantes para a perpetuação da condição de subalternidade. 
Nesta pesquisa trabalhamos com o conceito de subalternidade a partir das contribuições de Gayatri Spivak e Edward Thompson. Para a citada autora, os subalternos correspondem aos alijados da fala, às "camadas mais baixas da sociedade constituídas pelos modos específicos de exclusão dos mercados, da representação política e legal, e da possibilidade de se tornarem membros plenos no estrato social dominante" (SPIVAK, 2012, p.14). Para Thompson (2011), a subalternidade está associada ao conceito de experiência, da trajetória enquanto classe em uma determinada formação social. Seguindo formulação de Antonio Gramsci (referindo-se ao proletariado), é aquele que está alijado do poder, ou seja, "aquele cuja voz não pode ser ouvida" e que, portanto, não pode ocupar uma categoria monolítica e indiferenciada, por ser irredutivelmente heterogêneo.

Consideramos nesta pesquisa que o consumo acaba por ter um papel determinante não apenas sobre o cotidiano dos indivíduos, mas também nas formas como estes/as estruturam ou reforçam elementos identitários e estabelecem relações. Neste sentido, para a análise de como os sujeitos se movimentam em meio a esta ordem social, retomamos Certeau (1994) Para compreensão destas mulheres como produtoras de significados, com cotidianos marcados por sucessivos e recorrentes enfrentamentos ao sistema, sejam eles de maior ou menor intensidade, corpos vivos e desejantes, cotidianos de resistência, não apenas de mera e passiva apropriação uniforme, feita de puro conformismo às imposições do mercado e dos poderes sociais

\section{REFERÊNCIAS}

BORGES, Ivna. Mães encarceradas: onde estão seus filhos? Um estudo de caso em uma unidade prisional de Recife - PE. Viçosa: UFV, 2003

BRASIL. Constituição da República Federativa do Brasil, 1988. de 1940

Código Penal. Decreto Lei $\mathrm{n}^{\circ} 2.848$, de 07 de dezembro

. Código de Processo Penal. Decreto Lei no 3.689 , de 3 de outubro de 1941.

. LEP - Lei de Execução Penal - Lei 7210/1984.

Secretaria Especial de Políticas para Mulheres. III Plano Nacional de Política para as Mulheres. Brasília, 2013.

Ministério da Justiça. Levantamento Nacional de Informações Penitenciarias -Infopen. 2014a. Disponível em: https://goo.gl/mCK6n9. Acesso em: 13/03/2018.

Ministério da Justiça. Levantamento Nacional de Informações Penitenciárias -Infopen Mulheres. 2014b. Disponível em: <https://goo.gl/thRa3wAcesso em: 13/03/2018.

Ministério da Justiça. Levantamento nacional de informações penitenciárias - Infopen mulheres, 2ed. Disponível em: $<\quad$ http://depen.gov.br/DEPEN/depen/sisdepen/infopenmulheres/infopenmulheres_arte_07-03-18.pdf >. Acesso em : $11 / 07 / 2018$.

CERNEKA, H. A. Homens que mestruam: considerações acerca do sistema prisional às especificidades da mulher. Veredas do Direito: Direito Ambiental e Desenvolvimento, Belo Horizonte, v.6, n. 11, p. 61-78, 2009. 


\section{Raquel Aragão Uchôa Fernandes, Maria Lygia Almeida e Silva Koike,}

Michelle Cristina Rufino Maciel, Laura Susana Duque-Arrazola

CERVO, Amado Luiz; BERVIAN, P. A.; SILVA, da R. Metodologia científica -6. Ed.- São Paulo: Pearson Prentice Hall, 2007.

CHARNOUX, Ofélia Maria Guazzelli. Metodologia: processo de produção, registro e relato de conhecimento. $3^{\text {a }}$ Ed. São Paulo: DVS, 2006.

COLARES, L. B. C.; CHIES, L. A. B. Mulheres nas so(m)bras: invisibilidade, reciclagem e dominação viril em presídios masculinamente mistos. Estudos Feministas, Florianópolis, v. 18, n. 2, p. 407-423, 2010.

DOTTI, René Ariel. A crise do sistema penitenciário. Artigos de Direito, 2003. Disponivel em: HTTP://www.egov.ufsc.br/portal/sites/default/files/anexos/1244112442-1-PB.pdf. Acessado em: 25/03/2018.

FAERMAM, Lindomar, Pesquisa Participante no âmbito das Ciencias Sociais. Revista de Ciências Humanas, UNITAU, vol. 17. $\mathrm{N}$ 1, pp 41- 56, Jan/Jun 2014. Disponível: https://www.rchunitau.com.br/index.php/rch/article/viewFile/121/69 . Acesso 01 de novembro 2018

FERREIRA, Simone de Figueiredo. A diferenciação entre adolescente que cumpre medida socioeducativa e a mulher que cumpre pena no sistema penitenciário. In: Mecanismo estadual de prevenção e combate à tortura: relatório temático: um olhar sobre o encarceramento feminino. Recife: CEPE, 2017.

FARIAS, Emili Caroline Cota de Jesus. Maternidade no cárcere. Revista Jus Navigandi, ISSN 1518-4862, Teresina, ano 23, n. 5636, 8 mar. 2018. Disponível em: https://jus.com.br/artigos/62457. Acesso em: 19/03/2018.

GODOI, Rafael. Ao redor e através da prisão: cartografias do depositivo carcerário contemporâneo. Dissertação apresentada ao Program de Pós-Graduação de Sociologia da Universidade Faculdade de Filosofia, Letras e Ciências Humanas da Universidade de São Paulo - USP. São Paulo, 2010. Disponível em:Http//:www.teses.usp.br/teses/disponiveis/8/8132/.../2010_Rafae lGodoi.pdf. Acesso em: 13/03/2018

GRECO, Rogério. Direitos Humanos, sistema prisional e alternativas à privação de liberdade. São Paulo: Saraiva, 2011.

KOIKE, Maria Lygia. Maternidade e Gravidez no sistema prisional de Pernambuco. In: In: Mecanismo estadual de prevenção e combate à tortura: relatório temático: um olhar sobre 0 encarceramento feminino. Recife: CEPE, 2017.

MELLO, Daniela Canazaro de. A prisão feminina: gravidez e maternidade, um estudo da realidade em Porto Alegre - RS/Brasil e Lisboa/Portugal. Tese de Doutorado - Programa de Pós-Graduação em Ciências Criminais, Faculdade de Direito, Universidade Católica do Rio Grande do Sul. Porto Alegre, 2014.

MONTEIRO, Marília. A saúde da mulher privada de liberdade. In: Mecanismo estadual de prevenção e combate à tortura: relatório temático: um olhar sobre o encarceramento feminino. Recife: CEPE, 2017.

MECANISMO Estadual de Prevenção e Combate à Tortura de Pernambuco - MEPCT/PE. Relatório Temático 2016: Um olhar sobre o encarceramento feminino. Recife, 2016. CEPE. Companhia Editorial de Pernambuco.

MOURA, Danieli Veleda. A crise do Sistema Carcerário Brasileiro $e$ sua conseqüência na ressocialização do apenado. JV Jus Vigilantibus, S/D. Disponível em: HTTP://jusvi.com/artigos/40365. Acessado em: 11/10/2017

OLIVEIRA, Érika Patrícia Teixeira de. MULHERES EM CONFLITO COM A LEI: representações sociais, identidades de gênero $e$ letramento. Disponível em: http://www.ple.uem.br/defesas/pdf/eptoliveira.pdf. Acesso em: 13/03/2018.

PAZ, Carlos Eduardo Barbosa ...et al... Habeas Corpus(143.641): Todas as mulheres submetidas à prisão cautelar no sistema 
penitenciário nacional, que ostentem a condição de gestantes, de puérperas ou de mães com crianças até 12 anos de idade sob sua responsabilidade, e das próprias crianças.Defensoria pública da união, Brásilia, 2017. Disponivel em: www.stf.jus.br/portal/processo/verProcessoAndamento.asp?numero $=143641 \&$ classe $=$ HC\&origem $=$ AP\&recurso $=0 \&$ tipoJulgamentocias .Acessasdo em: 19/03/2018

POSADA, Rafael Andrés Urrego. Mulher, raça e encarceramento massivo no Brasil. In: Sistema Prisional: teoria e pesquisa. Org: Fernando Fidalgo e Nara Fidalgo. Belo Horizonte, Editora UFMG, 2017.

RIBEIRO DE OLIVEIRA, Luciana Maria. 2014. Crime é coisa de mulher: identidades de gênero e identificações com a prática de crimes em posição de liderança entre mulheres jovens. Recife: Novas Edições Acadêmicas. 258 pp.

SANTA CRUZ, Mariana; KOIKE, Maria Lygia; NEGROMONTE, Pércio; FIGUEIREDO, Simone. Das visitas ao sistema prisional. In: Relatório anual do mecanismo estadual de prevenção e combate à tortura de Pernambuco. Recife: CEPE, 2017.

SENA Maria Clara de, et al. Relatório Temático 2016: um olhar sobre o encarceramento feminino, Equipe MEPCT/PE, Recife, 2017

SPIVAK, Gayatri. Pode o subalterno falar? Belo Horizonte: Editora UFMG, 2010. 